\title{
ОСОБЕННОСТИ РАЗРАБОТКИ МЕСТОРОЖДЕНИЯ Х
}

\section{С. Н. Нагаева}

Под системой разработки нефтяного месторождения принято понимать комплекс технологических и технических мероприятий, обеспечивающих управление процессом разработки залежей нефти и направленных на достижение высокой выработки запасов нефти из продуктивных пластов при соблюдении условий охраны недр [1]. Проектирование разработки любого месторождения заключается в подборе такого варианта, который бы отвечал требованиям рациональной системы разработки. Исходя из вышесказанного, можно принять за рациональную систему разработки такую систему, которая может (и должна) обеспечить заданную планом добычу нефти при минимальных затратах и возможно больших коэффициентах нефтеотдачи.

Рассмотрим особенности разработки одного из месторождений Западной Сибири. Нефтяное месторождение Х открыто в 1993 г., в пробную эксплуатацию введено в 2006 г., в промышленную эксплуатацию - в 2008 г.

Географически месторождение расположено на юге Западно-Сибирской низменности в пределах Уватского административного района юга Тюменской области. Географически находится на левобережье р. Иртыш на низком заболоченном участке, южнее низовий р. Конда. Территория относится к Среднеобской низменности, существенно заболочена и заозерена. В целом можно констатировать, что месторождение X находится в районе со слабо развитой инфраструктурой.

Недропользователем является нефтяная компания ООО «Газпромнефть-Хантос». Оперативный подсчёт запасов месторождения производился в 1997, 2007, 2008, 2010, 2011 и 2012 годах. Первая технологическая схема разработки месторождения Х составлена в 2009 г. На рисунке 1 показана геологическая модель месторождения по основному продуктивному пласту Ү.

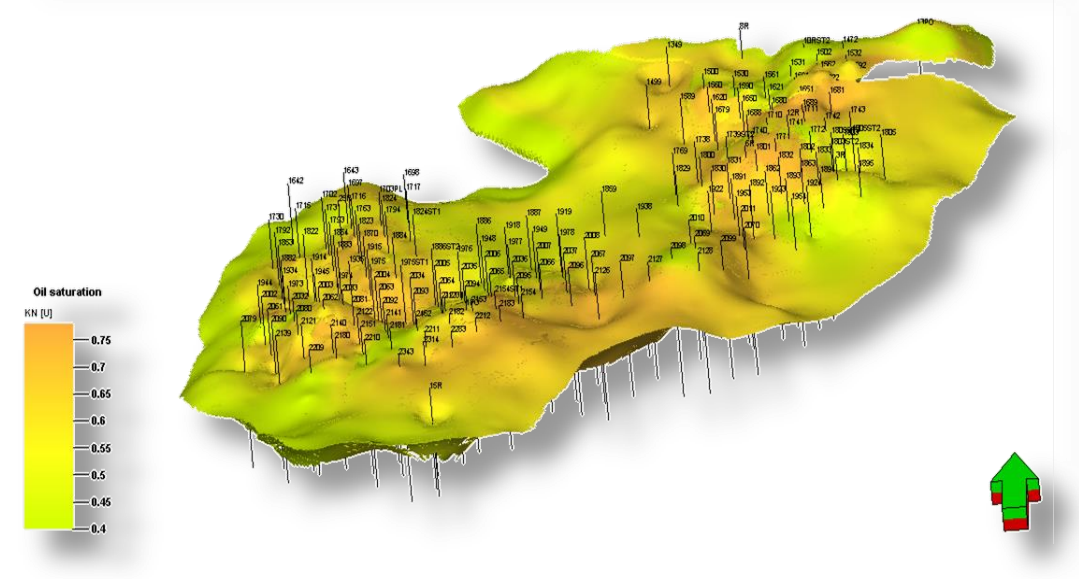

Рисунок 1 - Трехмерная геологическая модель месторождения X объекта Y

В тектоническом отношении месторождение приурочено к Фроловскому геоблоку, при этом его восточная часть приходится на западный борт Ханты-Мансийской котловины. Промышленная нефтеносность установлена в отложениях черкашинской свиты (пласт Ү).

Залежи характеризуются сложной геометризацией. Сложное геологическое строение характеризуется клиноформным строением пласта и высокой расчлененностью нижней части разреза (рис. 2). 


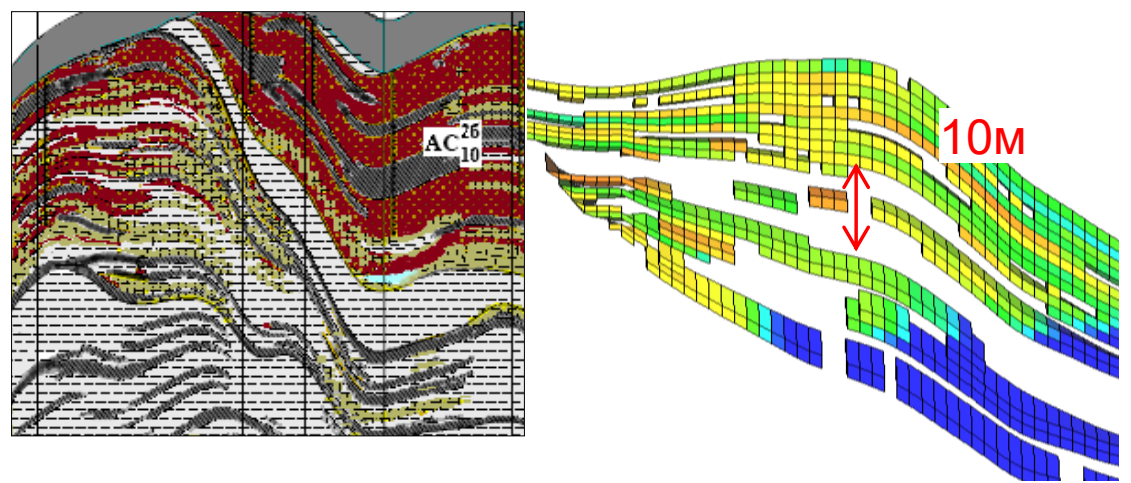

Рисунок 2 - Часть пласта, показывающая клиноформное строение и расчлененность нижней части разреза пласта $\mathrm{Y}$

В таблице 1 отражены основные геолого-физические характеристики основного пласта Ү.

\section{Геолого-физическая характеристика пласта Y}

\begin{tabular}{|l|c|}
\multicolumn{1}{|c|}{ Параметры пласта } & Объект Y \\
\hline \multicolumn{1}{|c|}{ Тип залежи - литологически экранированный } \\
\hline \multicolumn{1}{|c|}{ Тип коллектора - терригенный поровый } \\
\hline Площадь нефтеносности, м & 136652 \\
\hline Средняя глубина залегания кровли (а.о.), & 2316,2 \\
\hline \multicolumn{1}{|c|}{} & \\
\hline Средняя общая толщина, м & 29,3 \\
\hline Средняя эффектив. нефтенасыщ. толщина, м & 6,7 \\
\hline Коэффициент пористости, доли ед. & 0,20 \\
\hline Проницаемость, ГдИС/ГИС мкм2*10-3 & $14.5 / 26.7$ \\
\hline Начальная пластовая температура, 0С & 74 \\
\hline Начальное пластовое давление, МПа & 23,4 \\
\hline Вязкость нефти в пласт. условиях, мПа*с & 2,0 \\
\hline Плотность нефти в пласт. условиях, т/м3 & 0,811 \\
\hline Абсолютная отметка ВНК, м & $2310,6-2328,4$ \\
\hline Объемный коэффициент нефти, доли ед. & 1,09 \\
\hline Содержание серы в нефти, \% & 2,2 \\
\hline Содержание парафина в нефти, \% & 2,1 \\
\hline Давление насыщения нефти газом, МПа & 8,1 \\
\hline Газосодержание, м3/т & 36,5 \\
\hline Коэффициент продуктивности, м3/сут*МПа & 2,0 \\
\hline
\end{tabular}

\section{Показатели разработки месторождения X}

По состоянию на начало 2013 г. на месторождении пробурено 178 скважин, в том числе 89 добывающих (79 действующих, 3 в освоении после бурения, 1 наблюдательная, 3 в консервации и 3 ликвидированные), 84 нагнетательных (44 действующие, 40 в отработке на нефть) и 5 специальных (4 водозаборных, 1 поглощающая). Пробуренный фонд скважин превышает проектное значение. По проекту - 152 скважины, по факту - 163 скважины, однако количество действующих добывающих скважин меньше на 4 скважины, что составляет 
$3 \%$ (по проекту - 123, по факту - 119). К началу 2013 года на месторождении добыто 2517 тысяч тонн нефти (по проекту - 2456 тысяч тонн). Текущий коэффициент извлечения нефти - 0,036 (по проекту - 0,042), отбор от начальных извлекаемых запасов нефти - 10,22 \% (по проекту - 12,33\%). Обводненность по месторождению достаточно высокая и составляет $50,3 \%$ (по проекту - 44,5\%). Текущее пластовое давление - $22 \mathrm{MПа} \mathrm{-} \mathrm{за} \mathrm{период} \mathrm{разработки}$ снизилось на 1,4 МПа (начальное - 23,4 МПа).

$\mathrm{B}$ целом разработка месторождения Х осуществляется в соответствии с проектными решениями, основные технологические показатели выполняются:

- в настоящее время ведётся активное разбуривание и освоение новых площадей;

- система разработки находится на стадии формирования;

- основной объект Ү находится на стадии растущей добычи нефти.

Все показатели контролируются. Главная задача контроля за разработкой нефтяного месторождения - определение и отработка методов регулирования разработки месторождения для достижения проектных показателей [1]. Основными материалами, на которых основываются предложения по регулированию разработки месторождения, являются карты разработки и карты изобар.

На рисунке 3 изображена карта текущего состояния разработки основного пласта Ү, где показано расположение добывающих и нагнетательных скважин. Карта построена на основании текущего дебита нефти и воды скважин. Непосредственно на карте значение дебита выражается радиусом круга, вычерчиваемого на плане расположения скважин.

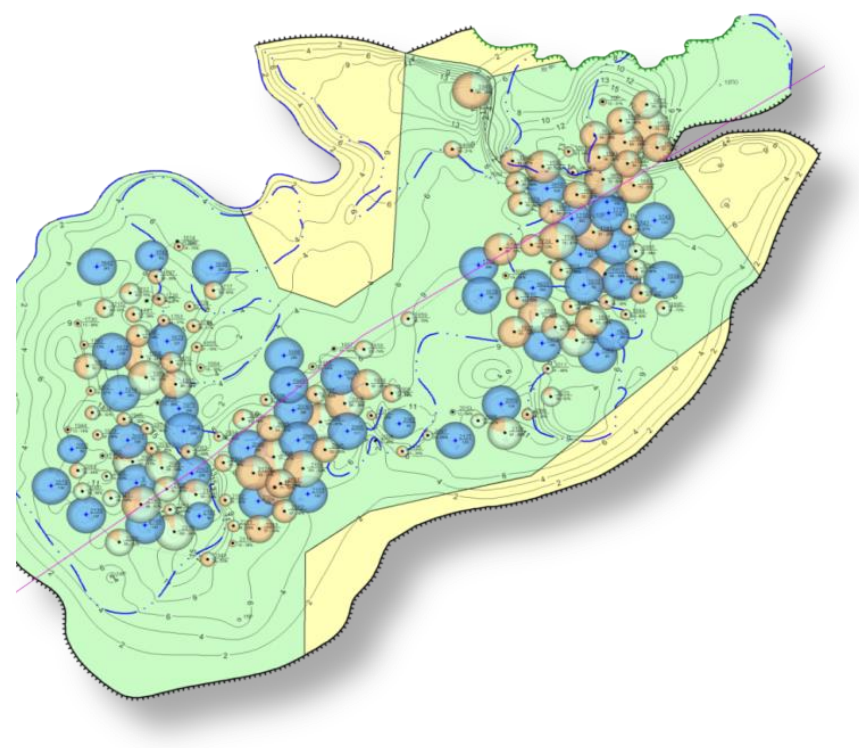

Рисунок 3 - Карта текущего состояния разработки пласта $\mathrm{Y}$

Итак, месторождение X характеризуется высокой степенью изученности: проведена $3 Д$ сейсмика, проведен равномерный охват разведочным бурением, проводится изучение свойств коллектора и флюида. Необходимо отметить:

- эксплуатационное бурение сосредоточено в центральной части пласта (30 \% от площади), следовательно, имеются дополнительные риски при разбуривании краевых участков месторождения;

- основной пласт Y имеет сложное клиноформное строение и представлен переходной зоной, к подошвенной части разреза расчлененность увеличивается, а нефтенасыщенность уменьшается до уровня остаточной, следовательно, мы наблюдаем повышенную обводненность продукции;

- более 35 \% извлекаемых запасов сосредоточено в коллекторах с проницаемостью менее 10 мД, следовательно, необходимо предусмотреть интенсификацию добычи нефти.

Рассмотрим, как реализуется последнее мероприятие (интенсификация добычи нефти) на месторождении X. 
Интенсификация добычи нефти тесно связана с проведением геолого-технических мероприятий (ГТМ). По состоянию на начало 2013 года проведено 181 ГТМ на 158 скважинах. Ежегодный объем проведения ГТМ составляет 2-63 скважино-операций, дополнительная добыча нефти с учетом переходящего эффекта равна 4,3-752,8 тысяч тонн и изменяется по годам от 36,9 до $92,4 \%$, в среднем составляя $80,1 \%$ от всей годовой добычи по месторождению. Основной вид ГТМ на месторождении - это гидравлический разрыв пласта (ГРП) в новых скважинах. В таблице 2 и на рисунке 4 отражены виды ГТМ, проводимые на месторождении X за все время разработки.

Таблица 2

Виды геолого-технических мероприятий

\begin{tabular}{|c|c|c|c|c|}
\hline \multicolumn{2}{|c|}{ Вид ГТМ } & \multicolumn{2}{|c|}{ 2006-2012 гг. } & \multirow{2}{*}{$\begin{array}{c}\text { Откло- } \\
\text { нение, \% }\end{array}$} \\
\hline & & проект & факт & \\
\hline \multirow[t]{2}{*}{ ГРП } & количество, шт. & 136 & 162 & +23 \\
\hline & доп. добыча, тыс.т & 1007,3 & 2130,1 & $+1122,8$ \\
\hline \multirow[t]{2}{*}{ Горизонтальные скважины } & количество, шт. & 2 & 1 & -1 \\
\hline & доп. добыча, тыс.т & 17,7 & 5,5 & $-12,2$ \\
\hline \multirow[t]{2}{*}{ Физико-химические методы (ОПЗ) } & количество, шт. & 2 & 0 & -2 \\
\hline & доп. добыча, тыс.т & 4,2 & 0 & $-4,2$ \\
\hline \multirow[t]{2}{*}{ Потокоотклоняющие технологии } & количество, шт. & 0 & 3 & +3 \\
\hline & доп. добыча, тыс.т & 0 & 4,1 & $+4,1$ \\
\hline \multirow[t]{2}{*}{ Ремонтно-изоляционные работы } & количество, шт. & 3 & 0 & -3 \\
\hline & доп. добыча, тыс.т & 1,4 & 0 & $-1,4$ \\
\hline \multirow[t]{2}{*}{ Перфорационные методы } & количество, шт. & 6 & 0 & -6 \\
\hline & доп. добыча, тыс.т & 3,2 & 0 & $-3,2$ \\
\hline \multirow[t]{2}{*}{ Оптимизация } & количество, шт. & 5 & 15 & +10 \\
\hline & доп. добыча, тыс.т & 8,9 & 64,7 & $+55,8$ \\
\hline \multirow[t]{2}{*}{ ИТОГО } & количество, шт. & 157 & 181 & +24 \\
\hline & доп. добыча, тыс.т & 1042,7 & 2204,4 & $+1161,7$ \\
\hline
\end{tabular}

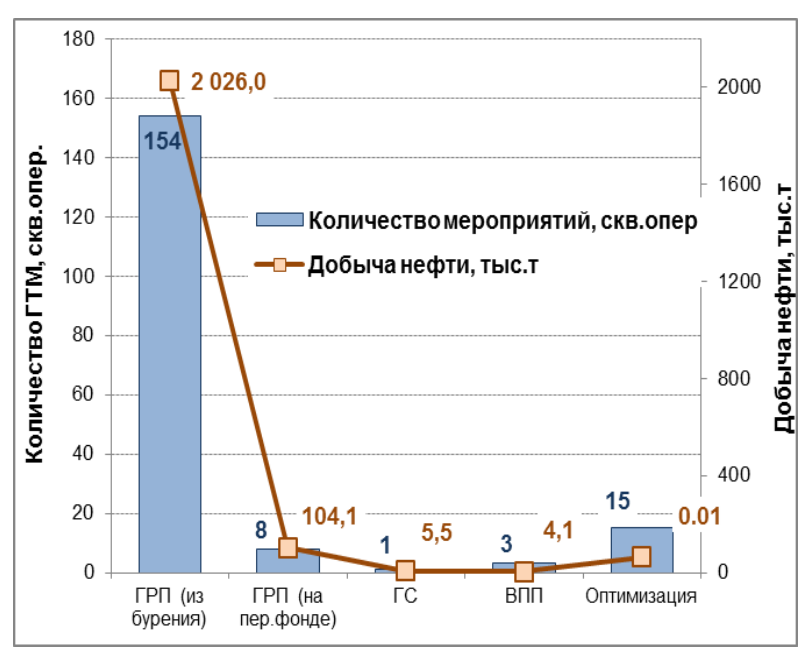

Рисунок 4 - Соотношение выполненных геолого-технических мероприятий 


\section{Анализ проведения ГРП}

В настоящее время ГРП широко применяется во всем мире как в низкопроницаемых, так и в высокопроницаемых пластах коллекторов. На месторождении Х данное мероприятие входит в число ГТМ для интенсификации добычи нефти. На практике считается, что в любой технически исправной скважине, в которой дренирует неистощенный пласт с проницаемостью ниже 0,05 мкм $^{2}$, может быть применен ГРП, дающий хороший экономический эффект при соблюдении технологии. В зависимости от целей различают несколько видов ГРП:

- однократный - для создания одной трещины в продуктивном пласте;

- многократный - для образования большого количества трещин;

- направленный (поинтервальный) - для создания трещин в определенных интервалах пласта;

- многосекционный (МГРП) - для создания трещин в горизонтальном участке ствола скважины (рис. 5).

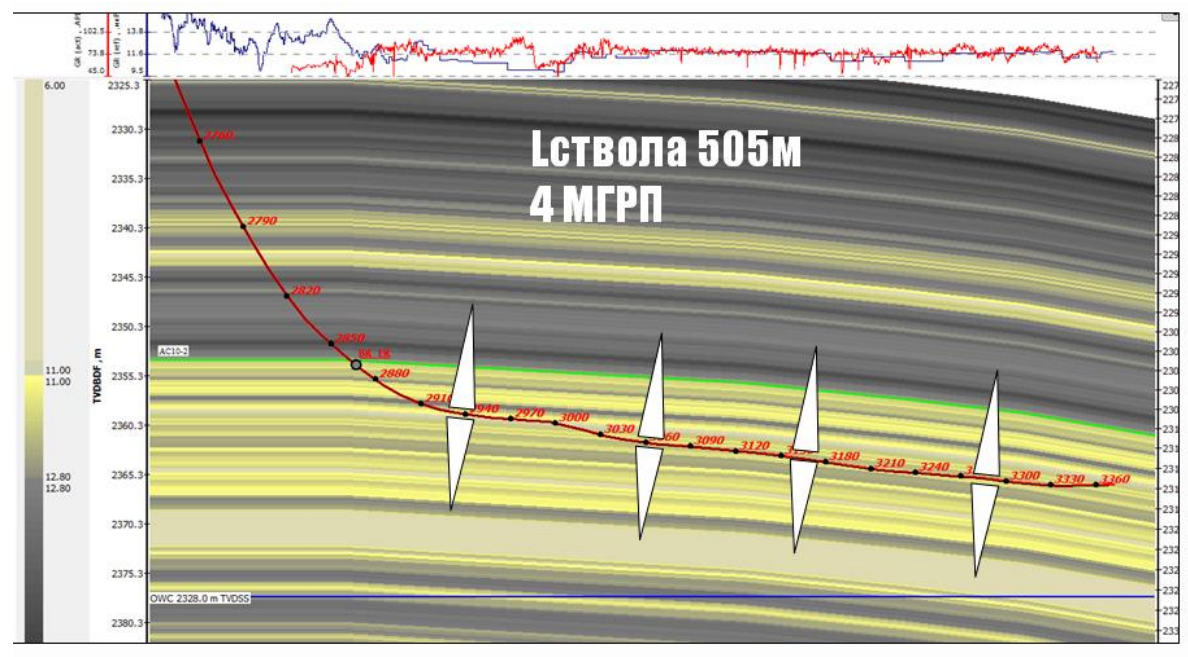

Рисунок 5 - МГРП в горизонтальной части ствола скважины

Для месторождения X формирующаяся система разработки наклонно-направленными скважинами с ГРП недостаточно эффективна для достижения утвержденного коэффициента извлечения нефти. В водонефтяных зонах данная система разработки показывает наименьшую эффективность, что видно из таблицы 3 , в которой показана средняя обводненность по месторождению, которая значительно увеличилась с годами.

Таблица 3

Дизайн ГРП и средняя обводненность скважин после ГРП

\begin{tabular}{|c|c|c|c|c|c|c|c|}
\hline годы & $\begin{array}{c}\text { закачено } \\
\text { пропан-та, т }\end{array}$ & $\begin{array}{c}\text { кол-во } \\
\text { скажин с } \\
\text { ГРП }\end{array}$ & $\begin{array}{c}\text { закачка } \\
\text { пропанта на } \\
\text { 1 скв., т }\end{array}$ & $\begin{array}{c}\text { уд. масса } \\
\text { пропанта на } \\
\mathbf{1} \text { м н/нас } \\
\text { толщины, т }\end{array}$ & $\begin{array}{c}\text { длина тре- } \\
\text { шины, м }\end{array}$ & $\begin{array}{c}\text { раскрытость } \\
\text { трещины, } \\
\text { мм }\end{array}$ & $\begin{array}{c}\text { средняя об- } \\
\text { воднен- } \\
\text { ность, \% }\end{array}$ \\
\hline 2007 & 507 & 8 & 63.4 & 6.7 & 124 & 3.8 & 9.9 \\
\hline 2008 & 511 & 9 & 56.8 & 6.1 & 94 & 4 & 28 \\
\hline 2009 & 1250 & 25 & 50 & 6.5 & 112 & 3.8 & 39 \\
\hline 2010 & 2197 & 34 & 64.6 & 9.2 & 135 & 7 & 39.3 \\
\hline 2011 & 2613 & 50 & 52.3 & 6.3 & 123 & 4.1 & 50 \\
\hline 2012 & 1612 & 23 & 65 & 6.8 & 126 & 4.2 & 38.5 \\
\hline
\end{tabular}

Таким образом, особенностью разработки месторождения Х является сложное геологическое строение, которое характеризуется клиноформным строением пласта и высокой расчлененностью нижней части разреза. И на сегодняшний момент перед недропользователем стоит основная проблема разработки месторождения $\mathrm{X}$ - это повышенная обводненность 
продукции новых и переходящих скважин. Причина: насыщение пласта Y соответствует переходной зоне, то есть коллектор пласта недонасыщен (большое количество рыхлосвязанной воды), и в подошвенной части нефтенасыщенность соответствует остаточной. При проведении ГРП в разработку вовлекается рыхлосвязанная водонасыщенность, и начинает активно работать подошвенная часть коллектора. Возможное решение проблемы: учитывая низкую продуктивность скважин, отказаться от ГРП невозможно; необходимо изменить характер притока по разрезу, увеличив его интенсивность в кровельной части пласта, для этого необходимо применение скважин с горизонтальным окончанием в кровельной части пласта.

Общие выводы по анализу разработки месторождения X.

- Разработка месторождения характеризуется растущей добычей нефти, что обусловлено активным разбуриванием месторождения и освоением новых площадей.

- Реализация проектного фонда составляет $36 \%$, уровни добычи нефти и ввод новых скважин из бурения соответствуют проектным уровням на протяжении всей эксплуатации месторождения.

- На месторождении отсутствует бездействующий фонд, неработающий фонд составляет 1,7 \%. Коэффициенты использования и эксплуатации фонда близки к единице.

- Выработка месторождения составляет 10,2 \% (разбуренная часть - $17 \%$ ), обводненность продукции значительно опережает выработку и составляет 50,3\%.

- Энергетическое состояние объекта удовлетворительное, снижение пластового давления от первоначального составило $6 \%$.

Исходя из вышесказанного, можно предложить следующие рекомендации:

1) проектный фонд скважин для бурения, расположенный в приконтурных, а также «неуверенных» в геологическом отношении зонах, считать зависимым от результатов бурения первоочередных ближайших скважин;

2) в зонах со сложным геологическим строением, при необходимости, изменять конструкцию отдельных добывающих горизонтальных скважин на наклонно-направленные; в случае неэффективного бурения горизонтальной скважины заменить бурение горизонтальных скважин на наклонно-направленные;

3) направление горизонтального участка скважины и его длину уточнять на основе текущего анализа геологического строения;

4) конструкцию окончания зарезки бокового ствола и длину горизонтальных участков боковых стволов уточнять на основе текущего анализа геологического строения.

\section{Литература}

1. Акульшин, А.И. Эксплуатация нефтяных и газовых скважин [Текст] / А. И. Акульшин. - М. : Недра, 1989.

2. Промысловые данные по разработке месторождения X, 2008-2013 гг. 